loyal Roman Catholic, he tried hard to reconcile his thoughts with contemporary orthodoxy, though it must be obvious that the theme demanded no more than a Deus Philosophorum, rather than the theistic conceptually obedient attitude of Pascal.

The author carefully avoids judging these savants of the seventeenth century by present-day standards, but one cannot help being struck by how closely the "suspension" of Malebranche lies to Husserl's phenomenological reduction or, put more simply, the process of waived judgment. Above all, and of signal merit in a book of this character, the reader knows exactly what the argument was, and is left with no loose ends.

In Britain, it is often the practice to ignore anything of a philosophic nature (even that of the early scholastics) between the Greeks and the rise of Cartesianism.

Naturally, these pages make no attempt to bridge this wide gap, but they reveal very clearly the fervent stream of philosophic endeavour which brought mankind to the edge of the abyss.

F. I. G. RAWLINS

\section{CARBIDES FOR HARDNESS}

\section{Strength of Hard Alloys}

By Gersh S. Kreimer. Translated from the Russian. Pp. viii +166. (Consultants Bureau: New York, 1968.) n.p.

HARD alloys, notably the tungsten carbides in combination with titanium, tantalum and othor earbides and bonded with cobalt metals, have been developed intensively over the past thirty-five years for use in the machine tool industry, rock drilling, armaments and other fields where wear resistance and strength are a necessity. These carbides have outstripped high speed steels for high metal cutting speeds although they are inferior to them in strength. The drawback of hard alloys, because of their brittleness and low ductility as compared with high speed steels, becomes especially evident in multi-edged hard alloy tools when the breakdown of a single edge necessitates replacement of the whole. In practice, it is usually necessary in machining metals to select a specifie hard alloy grade with the required minimum strength for the job. Many years ago it was found that alloying tungsten carbide with tantalum carbide brought about an increase in strength without loss of wear and improved the thermal shock and oxidation resistance.

Although the use of these complex carbides is very extensive in western countries, fow coordinated reviews on this range of carbides have been made.

This book reviews the literature in a very comprehensive way, although it probably does not do justice to all the relevant American and Swedish work. It correlates the data and links the basic information on property changes with current metallurgical theories such as the Griffiths/ Orowan crack theory and also the theories of dispersion hardening.

The first part of the book, chapters one and two, deals very comprehensively with the range of properties of the tungsten carbide-cobalt alloys showing the interrelationship with grain size, transverse rupture strength, bending, fatigue, compressive torsional and impact strengths. Correlations with hardness, wear resistance, elasticity and resistance to thermal shock are also given. This is followed by the analysis of the theories and the strength of these alloys. Chapters three and four deal with the ternary alloys, tungsten carbide-titanium carbide-cobalt, covering similar data and theories as in the first part but to a much more limited extent. The third section, chapters five and six, deals with the ternary tungsten carbidetantalum carbide-cobalt alloys in the same way. The book closes in chapter seven with a reference to the strengths of tungsten carbide-titanium carbide-tantalum carbide-cobalt alloys and the literature survey at the end cites some 198 original sources.

This book will prove very useful to anyone interested in a concise compendium and statement of the published mechanical and physical properties and of the underlying theories relating to the performance and strength of the complex carbide hard metals.

W. O. AleXANDer

\section{RADICAL ION CHEMISTRY}

\section{Radical lons}

Edited by E. T. Kaiser and L. Kevan. (Reactive Intermediates in Organic Chemistry.) Pp. ix +800 . (Interscience (Wiley): London, August 1968.) $280 \mathrm{~s}$.

THE second title in this series on "Reactive Intermediates in Organic Chemistry", under the general editorship of George A. Olah and Lester Friedman, is devoted to the chemistry of radical ions. The behaviour of the relatively stable aromatic radical ions which exist in solution is reasonably well known, but the editors have interpreted the definition of radical ions broadly, to include transition metal complex ions and various unstable organic and inorgunic species stabilized by trapping in solids.

The book consists of thirteen chapters by acknowledged experts in their various fields, which, taken together, form a comprehensive treatise. While much of the material reviewed is necessarily concerned with identification of the species by electron spin rosonance spectroscopy, and with the determination of spin densities for comparison with the predictions of molecular orbital theory, othor aspects are also discussed at length. The generation of radical ions by the familar methods of chemical and electrochemical oxidation and reduction, and by the use of ionizing radiation, the use of optical techniques for the identification of radical ions in organic and inorganic systems, and the reaetivity of these specios, are also discussed in several chapters.

The topics reviewed are: electron spin densities and their determination (James R. Bolton); metal ketyls and related radical ions including a discussion of the ion pair equilibria in which these species are involved (Nobru Hirota); semidone radical ions (Glen A. Russell); the e.s.r. spectra of radical carbons, with a short section on the preparation of these species (Gershon Vincow); orbital degeneracy in benzene and substituent effects as revealed by spin density determination - a fascinating discussion marred only by an execrable pun in the second line of the text (Kerry W. Bowers); aromatic anion radicals (M. Thomas Jones); organometallic radicals and ion radicals of the group IV elcments (Grant Urry); aromatic sulphurcontaining radical ions (M. M. Urberg and E. T. Kaiser); a discussion of ionic reactions in organic solids under $\gamma$-irradiation at $-196^{\circ}$ (William R. Hamill); a roview of recent work on the structures of inorganic doublet- and triplet-state radicals as revealed by electron spin resonance spectroseopy (Hilary J. Bower, M. C. R. Symons and D. J. A. Tinling); the fragmentation of irradiated inorganic solids, and the structural and other information which can be derived from such studies, including the development of a detailed mechanism for the radiolysis of inorganic nitrates (Joseph Cunningham); trapped radicals in inorganic glasses (A. Treinin); and electron spin resonance spectra of first row transition metal complex ions (H. A. Kuska and Max T. Rogers).

The date to which the literature is covered is not explicibly stated, but coverage appears to be fairly complete up to 1966, with some later references. Author and subject indexes are provided. The production is of a high standard and formulae, tables and diagrams are clear and well set out. The editors and publishers are to be congratulated on the care which they have obviously taken in 